\title{
Potential Sustainable Biomaterials Derived from Cover Crops
}

\begin{abstract}
Naresh Shahi, ${ }^{a}$ Gautam Joshi, ${ }^{\mathrm{b}}$ and Byungjin Min ${ }^{\mathrm{b}, *}$
Plant-derived biopolymers are renewable and readily available, thus making viable alternatives to synthetic polymers. The present study examined properties of biopolymers from cover crops such as rye, oat, clover, vetch, and barley, which were grown organically in a greenhouse. The yields of cellulose, hemicellulose, and lignin of the cover crops were calculated based on the dry weight. Structural variations and thermal properties of the isolated cellulose were characterized and compared with commercial cellulose using Fourier transform infrared (FTIR) spectroscopy, Raman spectroscopy, and Thermogravimetric analysis (TGA). The average yield percentages of cellulose, hemicellulose, and lignin were 19 to $27 \%, 9$ to $25 \%$, and 1.42 to $4.86 \%$, respectively. The FTIR and Raman spectral analysis indicated that the isolated cellulose had similar peaks and patterns to commercial cellulose, and confirmed the removal of non-cellulosic constituents. The onset decomposition temperature occurred at $270{ }^{\circ} \mathrm{C}$ in all samples. Interestingly, the maximum degradation temperature beyond $370{ }^{\circ} \mathrm{C}$ in cellulose was isolated from black oat, which was higher than commercial cellulose (350 $\left.{ }^{\circ} \mathrm{C}\right)$. The findings of this research suggest that cellulose isolated from cover crops may be a benefit to the polymer industry in the development of bio-based materials such as biofuels, bio-composites, and biomedical devices.
\end{abstract}

Keywords: Cover crops; Biopolymers; Lignocellulose; Cellulose

Contact information: a: Integrative Biosciences (IBS) Ph.D. Program, Tuskegee University, Tuskegee, AL, USA 36088; b: Department of Food and Nutritional Sciences, Tuskegee University, Tuskegee, AL, USA 36088; *Corresponding author: bmin@tuskegee.edu

\section{INTRODUCTION}

Growing global consumption of non-renewable fossil fuel and its derivatives, such as synthetic plastics, generates a significant amount of waste that has negative impacts on the environment. Plant biomass is a viable alternative option for reducing the use of fossil fuels and its byproducts. Common sources of plant biomass include agroindustry wastes, natural fibers, forestry bioproducts, and crops (Yahya et al. 2015; Dungani et al. 2017; Ajao et al. 2018). Agricultural residues are a renewable biomass which is a plentiful resource on earth (Das et al. 2014; Poletto et al. 2014). Lignocellulosic biomass mainly consists of cellulose, hemicellulose, and lignin, where cellulose is the most abundant (Panthapulakkal and Sain 2012). Cellulose has a wide range of applications including packaging materials, drug delivery, automotive and aircraft parts, and textiles (Mandal and Chakrabarty 2011; Siepmann et al. 2012; Asim et al. 2015; Ng et al. 2015; Dungani et al. 2017; Kauldhar and Yadav 2018).

Cover crops are fast-growing legumes or non-legumes that protect the soil against wind and water erosion, and improve soil fertility (Szerencsits et al. 2015). In addition to their positive impacts on soil quality, crop residues are also good sources of lignocellulosic 
plant biomass, and therefore used as feedstock for biofuel and biogas production (Stinner et al. 2008; Szerencsits et al. 2015). However, to improve and optimize usability of cover crop biomass as biomaterials, further information on material properties of the resulting cellulose derived from cover crops needs to be determined. In this context, conversion of cover crop residues into biomaterials may leverage efforts to scale up production of plant biomass, and to increase economic benefits of farmers and producers. Several techniques are available for the separation of lignocellulosic components, such as chemical (acid and alkali), physical (ball milling, ultrasonication, and high-pressure homogenization), and biological (enzyme hydrolysis) methods (Kumar et al. 2009; Behera et al. 2014; Qu et al. 2017; Bundhoo and Mohee 2018; Chandel et al. 2018; Seta et al. 2020). The chemical method with a detergent (neutral and acid) is useful to assess the contents of the lignocellulosic composition of the plant biomass (Soest and Robertson 1981; Qi et al. 2018).

Therefore, this study was conducted to screen biomass from organically grown cover crops as potential biomaterials. The screening process was performed by extraction, followed by estimation of lignocellulosic components such as hemicellulose, cellulose, and lignin. The structural variations and thermal properties of isolated cellulose were further evaluated using FTIR, Raman spectroscopy, and TGA. It is expected that the screening results will further support a better understanding of biopolymers extraction from cover crop residues, and their potential applications in the polymer industry.

\section{EXPERIMENTAL}

\section{Materials}

The cover crops were grown in a greenhouse in a $5 \mathrm{~kg}$ pot lined with a transparent plastic bag (to prevent leaching) filled with topsoil $(0$ to $15 \mathrm{~cm})$ that was collected from an organic farm at Tuskegee University. The cover crops tested were abruzzi rye (Secale cereal L.), black oat (Avena strigosa Schreb), crimson clover (Trifolium incarnatum L.), hairy vetch (Vicia villosa Roth.), and winter barley (Hordeum vulgare L.). Eight certified seeds of each cover crop were planted in each pot and raised to maturity, after which the biomass was cut above ground, dried at $65{ }^{\circ} \mathrm{C}$ for $72 \mathrm{~h}$, and ground to pass through a 149 $\mu \mathrm{m}$ sieve. Dried powder (raw) of cover crops was placed in a filter bag and treated with neutral detergent fiber (NDF) solution, acid detergent fiber (ADF) solution, alpha-amylase, and sodium sulfite. The ADF was further treated with alkaline hydrogen peroxide (AHP) solution, and the obtained pulp was labeled as cellulose followed by the sample names, for example, cellulose-rye, cellulose-oat, etc. The AHP solution was prepared by adding sodium hydroxide $(1 \mathrm{~N} \mathrm{NaOH})$ in $3 \%$ hydrogen peroxide $\left(\mathrm{H}_{2} \mathrm{O}_{2}\right)$. Commercially available cellulose (Avicel PH101, Sigma Aldrich, St. Louis, MO, USA) was used to track the physical, chemical, and thermal properties of isolated cellulose and labeled as cellulose-c.

\section{Extraction of Lignocellulose (Hemicellulose, Lignin, and Cellulose)}

The extraction of lignocellulosic components was conducted using a modified Van Soest method (Soest and Robertson 1981). Approximately $0.50 \mathrm{~g}$ of dried powder was encapsulated in a filter bag and treated with neutral detergent fiber solution and acid detergent fiber solution. Both treatments were performed at $100{ }^{\circ} \mathrm{C}$ for $1 \mathrm{~h}$ using a fiber analyzer (ANKOM Technology, Macedon, NY, USA). The NDF solution was used to solubilize the extractives, such as pectin and proteins. Alpha-amylase and sodium sulfite 
were added to remove starch and protein, respectively, and the ADF solution was used to dissolve the hemicellulose (Soest and Robertson 1981). The ADF was further treated in a glass beaker containing alkaline hydrogen peroxide (AHP) solution at an elevated $\mathrm{pH}$ (11.05) at $60{ }^{\circ} \mathrm{C}$ for $2 \mathrm{~h}$ to dissolve the lignin fraction. Then, the undissolved white pulp was collected as cellulose and washed with deionized water several times until it had a neutral $\mathrm{pH}$. Obtained cellulose was dried and analyzed for physical, chemical, and thermal properties. The following formula was used to estimate the wt $\%$ of each lignocellulose component and extractive,

$$
\text { Percentage of NDF/ADF }=100 \times\left(W_{3^{-}}\left(W_{1} \times C_{1}\right)\right) / W_{2}
$$

where $W_{1}$ is the bag tare weight, $W_{2}$ is the sample weight, $W_{3}$ is the dried weight of the bag containing fiber after the extraction process, and $C_{1}$ is the blank bag correction (running average of final oven-dried weight divided by original blank bag weight). Additional terms are defined below:

$\mathrm{NDF}=[$ Hemicellulose + Lignin + Cellulose + Silica- extractives (protein, fats, etc.) $]$

$\mathrm{ADF}=[$ Lignin + Cellulose + Silica- hemicellulose $]$

AHP $=[$ Cellulose-lignin and silica $]$

\section{Characterization of the Cellulose}

Attenuated total reflectance (ATR)-Fourier Transform infrared spectroscopy (FTIR)

Attenuated total reflectance Fourier transform infrared spectroscopy (ATR-FTIR) equipped with silver gated zinc selenite crystal (Thermo Electron Corporation, Madison, WI, USA) was used to obtain spectra patterns from the cover crops (raw) and isolated cellulose samples at room temperature. The experiments were carried out in the range of 650 to $4000 \mathrm{~cm}^{-1}$ with a resolution of $4 \mathrm{~cm}^{-1}$, and 48 scans were conducted per sample. The baseline was corrected before each sample measurements.

\section{Raman spectroscopy analysis}

Raw and isolated cellulose samples were analyzed using Raman spectroscopy (DXR Raman Spectroscopy Thermo Scientific, USA). This system was equipped with a $780 \mathrm{~nm}$ wavelength, $3.0 \mathrm{~mW}$ power laser. The spectra were recorded, and each spectrum presented is an average of 3 different points on the sample. The data acquisition was carried out in a range of 100 to $3500 \mathrm{~cm}^{-1}$, and 32 scans were accumulated in each sample with a $4 \mathrm{~cm}^{-1}$ spectral resolution. All graphs were baseline corrected ( 25 points) using OriginPro 2016 software (OriginLab Corporation, Version: 93E, Northampton, MA, USA).

\section{Thermogravimetric analysis}

Thermogravimetric analysis (TGA) was carried out using TGA Q50 (TA Instruments, New Castle, DE, USA). All raw and isolated cellulose samples were heated from 30 to $500{ }^{\circ} \mathrm{C}$ with a heating rate of $10{ }^{\circ} \mathrm{C} / \mathrm{min}$ under the nitrogen flow. Graphs were analyzed with OriginPro 2016 software.

\section{Statistical analysis}

Nine replications were performed for each of the treatments NDF, ADF, and AHP of every studied sample. The variances of collected data set with samples at each treatment 
were analyzed by repeated-measures analysis of variances (RM-ANOVA) using the general linear model procedure of the statistical system SAS version 9.4 (SAS Inst., Cary, NC, USA). Differences in mean dry weight of ADF, NDF, and recovered cellulose, as well as the effectiveness of treatments among the samples, were analyzed using Fisher's Protected least significant difference. The level of significance was defined at $\mathrm{P} \leq 0.05$.

\section{RESULTS AND DISCUSSION}

\section{Determination of Lignocellulosic Components}

As shown in Table 1, the hemicellulose, cellulose, and lignin content in cover crops ranged from 9 to $25 \%, 19$ to $27 \%$, and 1 to $5 \%$, respectively. The percentage of holocellulose (Hemicellulose + cellulose) contents in the cover crops indicated that the study samples might be good candidates as potential raw material for biopolymers. Nonlignocellulosic components from the subsequent sulfuric acid hydrolysis were removed as extractives, which might contain starch, pectin, proteins, lipids, and pigments (Godin et al. 2011). Alkaline hydrogen peroxide (AHP) treatment transformed ADF into cellulose, indicating that non-cellulosic components were removed. Macroscopically, colored components were changed to white after AHP treatment, presented in Fig. 1.

Table 1. Mean Dry Weight (\%) of Extractives, Lignocellulosic Components, NDF, and ADF of Cover Crops

\begin{tabular}{|c|c|c|c|c|c|c|}
\hline \multirow{2}{*}{ Cover crops } & \multicolumn{7}{|c|}{ Dry weight (\%) } \\
\cline { 2 - 7 } & Extractive & Hemicellulose & Cellulose & Lignin & NDF & ADF \\
\hline Abruzzi rye & 46.30 & 25.17 & $25.26^{\mathrm{a}}$ & 2.56 & $53.70^{\mathrm{a}}$ & $28.53^{\mathrm{b}}$ \\
\hline Black oat & 52.17 & 20.82 & $25.17^{\mathrm{a}}$ & 1.77 & $47.83^{\mathrm{b}}$ & $27.01^{\mathrm{c}}$ \\
\hline Crimson clover & 62.22 & 9.53 & $25.58^{\mathrm{a}}$ & 3.35 & $37.78^{\mathrm{c}}$ & $28.25^{\mathrm{b}}$ \\
\hline Hairy vetch & 53.71 & 14.29 & $27.24^{\mathrm{a}}$ & 4.86 & $46.29^{\mathrm{b}}$ & $32.00^{\mathrm{a}}$ \\
\hline Winter barley & 53.40 & 20.88 & $19.36^{\mathrm{b}}$ & 1.42 & $46.60^{\mathrm{b}}$ & $25.72^{\mathrm{d}}$ \\
\hline
\end{tabular}

abcd Treatment means within the columns with the different superscript differ at $(\mathrm{P}<0.05)$.

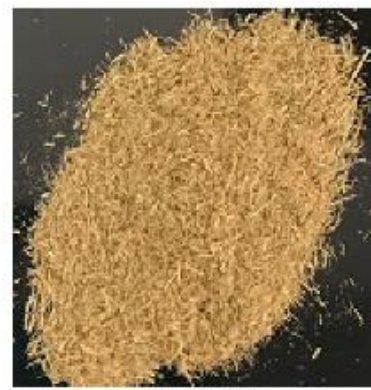

(a) Raw

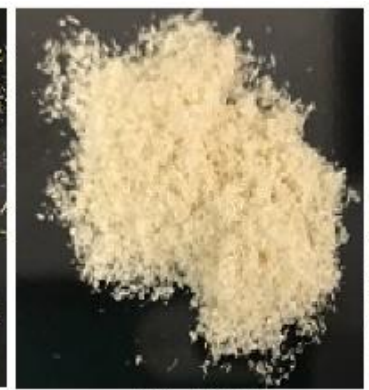

(b) ADF

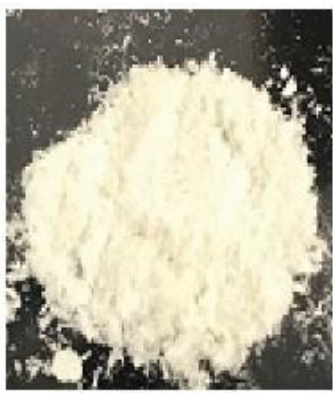

(c) Cellulose

Fig. 1. Visual transformation of cover crops during the cellulose extraction process: (a) raw, (b) $\mathrm{ADF}$, and (c) cellulose-alkaline hydrogen peroxide (AHP) treated

The mean NDF yield of the selected samples ranged from $37.7 \%$ to $53.7 \%$, as presented in Table 1. The yield of NDF was significantly different $(\mathrm{p} \leq 0.05)$ in abruzzi rye $(53.7 \%)$ and crimson clover $(37.8 \%)$, while there were no significant differences $(\mathrm{p} \geq$ 0.05 ) in the mean value of NDF among other cover crops. Overall, the yield of extractives 
was more than $50 \%$ (except aburuzzi rye), and the highest number of extractives was obtained from crimson clover $(62.2 \%)$. It was reported that NDF from triticales (a hybrid of wheat and rye) forages ranged from $35.5 \%$ to $68.7 \%$ (Coblentz et al. 2018). The high yield of extractives in the selected cover crops might be due to the immature harvest of the cover crops. The composition of lignocellulosic components could be varied by factors such as plant type, growth stage, and degree of maturation (Xu et al. 2019). Similarly, the ADF solution was used to remove hemicellulose. The average ADF yields ranged from $25.7 \%$ to $32.0 \%$. The ADF yields were significantly different $(\mathrm{p} \leq 0.05)$ among black oat, hairy vetch, and winter barley, while there was no significant difference between abruzzi rye and crimson clover. However, it was observed that the hemicellulose amount was the highest in abruzzi rye $(25.2 \%)$ and the lowest in crimson clover $(9.5 \%)$. A similar range of hemicellulose was reported in the study dealing with switchgrass, 25 to $34 \%$, and Sorghum, 11 to $28 \%$ (Rooney et al. 2007; van der Weijde et al. 2013).

The yield of lignin in cover crops ranged from 1.42 to $4.86 \%$. Due to the alkaline conditions during AHP hydrolysis, the compact structure of the lignocellulose relaxed and degraded by breaking the intermolecular ester bond between lignin and the carbohydrates (Johar et al. 2012; Lee et al. 2014). Lignocellulosic components may vary according to several factors such as storage conditions, harvesting time, growth conditions, and geographical regions of the plant biomass (Welker et al. 2015). The cellulose residue remained after AHP treatment, and it ranged from 19 to $27 \%$. The cellulose amount from winter barley was significantly less $(\mathrm{p} \leq 0.05)$ than the other cover crops. Interestingly, there were no significant differences $(\mathrm{p} \geq 0.05)$ in cellulose among abruzzi rye, crimson clover, black oat, and hairy vetch, in which cellulose was around 25 to $27 \%$. It is reported that a similar range of cellulose was found in miscanthus and switchgrass, which are perennial plants, and considered to be potential crops for biofuels and biochemicals (Rooney et al. 2007; Zhang et al. 2012; van der Weijde et al. 2013; Jin et al. 2017). Therefore, the obtained results from cover crops in this study may also be used for promising and sustainable feedstocks for biofuels and biopolymers production in the future. The FTIR and Raman Spectroscopy results further confirmed the purity of the isolated cellulose.

\section{Fourier transform infrared spectroscopy (FTIR) spectrum analysis}

As shown in Fig. 2(a) and (b), FTIR spectra were compared among the samples. The removal of non-cellulosic constituents with successive chemical treatments was confirmed from the pattern of spectra. The dominant peaks around 3300 and $2800 \mathrm{~cm}^{-1}$, due to $\mathrm{OH}$-stretching and $\mathrm{CH}$ - stretching of cellulose, were observed in the entire spectra. Similarly, sharper peaks were also detected at around $1031 \mathrm{~cm}^{-1}$ in all samples, and peaks are associated with the $\mathrm{C}-\mathrm{O}$ stretching of cellulose (Mandal and Chakrabarty 2011). Interestingly, those peaks were also present in raw samples, but the fact that the peaks were more defined and sharper in cellulose after AHP treatment indicated that the removal of non-cellulosic components occurred. Similarly, prominent peaks around 1627 and 1535 $\mathrm{cm}^{-1}$ from the raw samples disappeared in the cellulose samples, as presented in Fig. 2(c). It is conjectured that these peaks can be attributed either to the acetyl and uronic ester group of hemicellulose or the ester/ferulic groups of lignin (Subhedar and Gogate 2014). The results indicated that the applied treatment might increase the crystallinity of cellulose by removing lignin and hemicellulose. The increase of crystallinity and purity in cellulose is associated with increased stiffness and rigidity, which contributes to the strength of cellulose (Johar et al. 2012). FTIR-Raman spectroscopy has been used as a quantitative 
analytical tool to determine the crystallinity properties of cellulose (Schenzel et al. 2005; Poletto et al. 2014; Agarwal 2017). As expected, the peaks were more defined in all cellulose samples, the intensity around 1420 to $1430 \mathrm{~cm}^{-1}$ and around $900 \mathrm{~cm}^{-1}$ were prominent compared to raw samples shown as a magnified form in Fig. 2(c). The band at around 1420 to $1430 \mathrm{~cm}^{-1}$ is associated with the amount of the crystalline structure of the cellulose, while the band at around $900 \mathrm{~cm}^{-1}$ is assigned to the amorphous region in cellulose and the ratio between two bands was described as crystalline packaging of the chain (Akerholm et al. 2003). The findings of the result were further supplemented by Raman spectroscopy analysis, which is discussed in the following section.
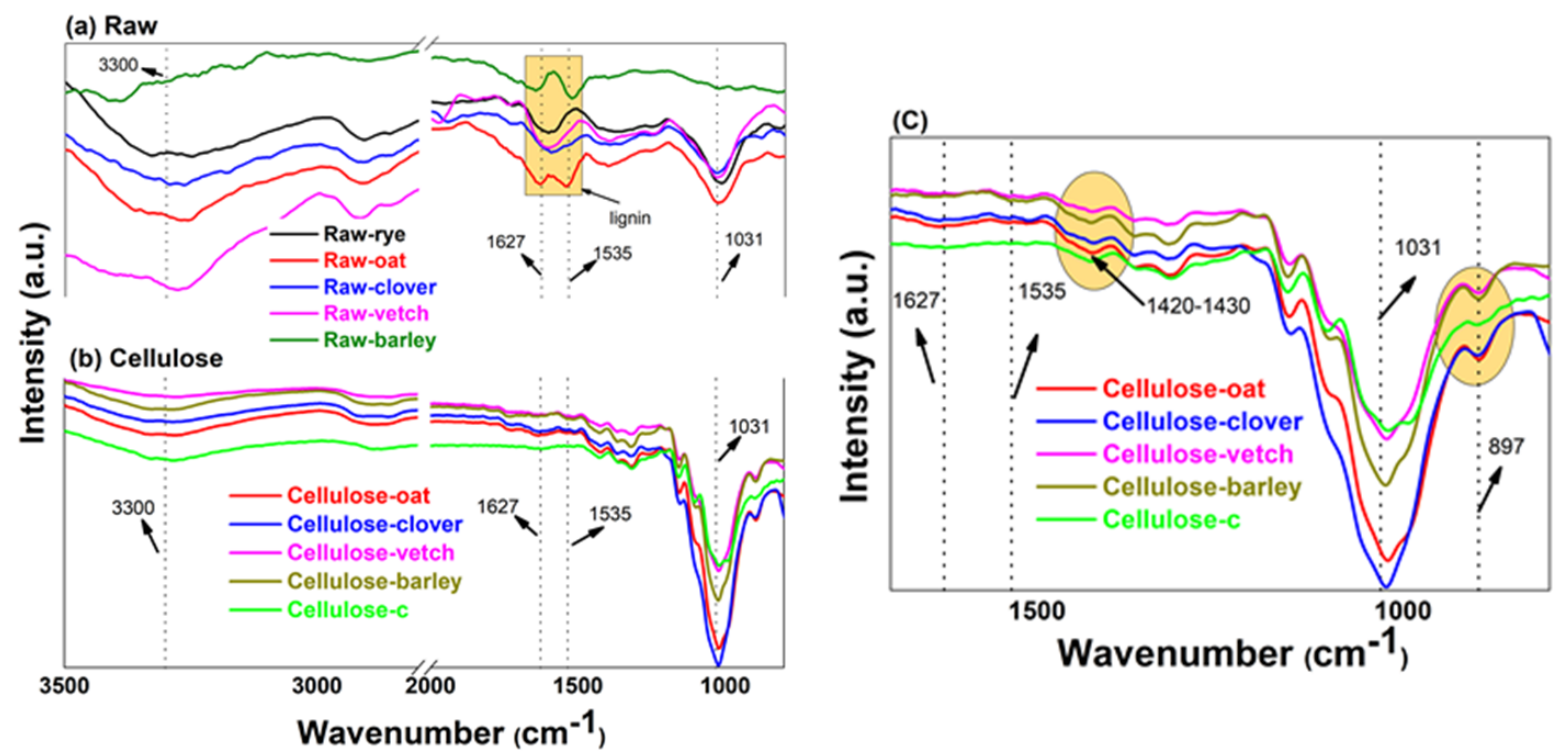

Fig. 2. Fourier transform infrared (FTIR) spectra of (a) raw-(top), (b) cellulose-AHP treated (bottom) from cover crops and commercial cellulose (Cellulose-c) and (c) magnified view of cellulose

\section{Raman spectroscopy spectrum analysis}

Raman spectroscopy is a non-destructive vibrational technique capable of providing structural information, qualitative, and quantitative measurement (Makarem et al. 2019). Raman spectra of cellulose from cover crops and commercial cellulose (cellulose-c) were collected and compared to the literature data. As shown in Fig. 3, an increase in the peak intensity consequently brings increased crystallinity in cellulose. In most cases, the peak's sharpness and intensity are associated with the crystallinity of cellulose. However, Raman frequency, intensity, and band shape of the vibrations may vary between the celluloses due to the differences in the chemical structure, interaction between the biopolymer chains, and its organizations (Agarwal 2017). Obtained spectra among cellulose-oat, cellulose-vetch, and cellulose-barley exhibited quite a similar peak intensity and patterns to commercial cellulose (cellulose-c) with a distinct peak around $1460 \mathrm{~cm}^{-1}$. However, it is reported that a Raman signal around $1462 \mathrm{~cm}^{-1}$ is due to the transition from crystalline to amorphous form (Schenzel et al. 2005). Raman spectrum from cellulose-rye was unusable may be due to the presence of contamination. Cellulose, a polysaccharide, is known to show a unique pattern of Raman bands from 300 to $3000 \mathrm{~cm}^{-}$ ${ }^{1}$ (Agarwal et al. 2013). The main cellulosic peaks are indicated with vertical dotted lines in Fig. 3, the corresponding peak at $899 \mathrm{~cm}^{-1}$ is associated with the $\mathrm{C}-\mathrm{H}$ ring disorder, and the peak at $1096 \mathrm{~cm}^{-1}$ is associated with the C-C and C-O stretching of cellulose structure 
(Lupoi et al. 2014). Bands from 1300 to $1500 \mathrm{~cm}^{-1}$ corresponding to the $\mathrm{CH}_{2}$ - and $\mathrm{CH}_{2} \mathrm{OH}$ deformations bands at $2889 \mathrm{~cm}^{-1}$, as well as $\mathrm{CH}$ and $\mathrm{CH}_{2}$, corresponding to stretching, were also reported (Agarwal 2017). Thus, the obtained Raman spectra complement the FTIR results in this study in which the isolated cellulose from cover crops have a similar structural properties with commercial cellulose. However, further investigation with Xray crystallography data are needed to explicate the crystallinity properties of the isolated cellulose. The use of simpler and more rapid spectroscopy methods such as Raman and Infrared has proved invaluable in analyzing biomass composition such as cellulose, hemicellulose and lignin for a wide range of applications to understand the biofuel feedstocks (Lupoi at al. 2014).

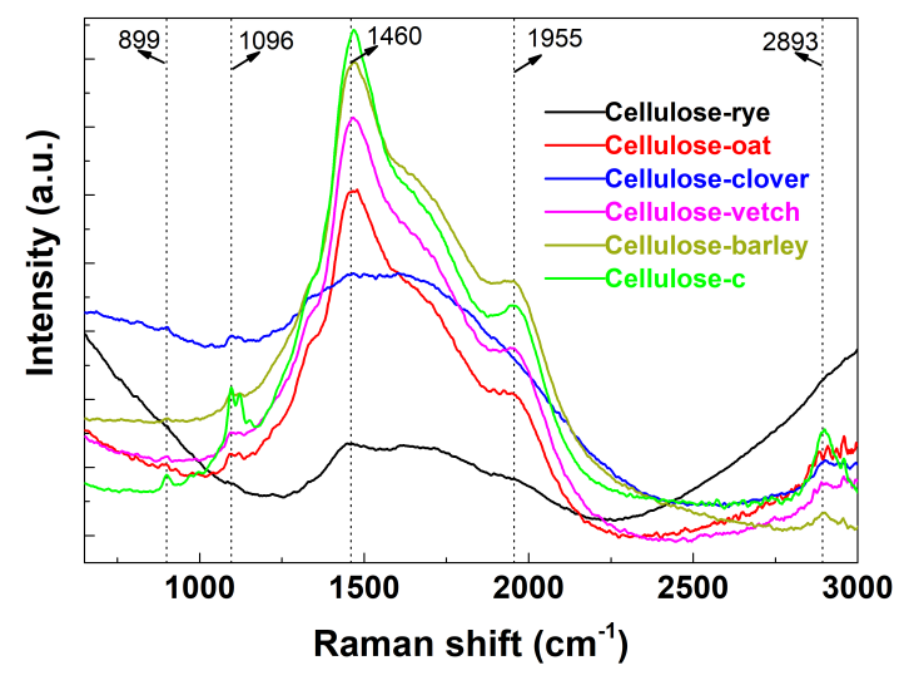

Fig. 3. Raman spectra of cover crops and commercial cellulose (cellulose-c)

\section{Thermogravimetric analysis (TGA)}

The thermal stability of the isolated cellulose was determined by TGA. As presented in Table 2, three major degradation processes occurred during pyrolysis, and temperature ranges were 90 to $110{ }^{\circ} \mathrm{C}, 250$ to $350{ }^{\circ} \mathrm{C}$, and 350 to $450{ }^{\circ} \mathrm{C}$. Regardless of the samples, the initial weight loss was around $5 \%$, which occurred below $110{ }^{\circ} \mathrm{C}$. This result corresponds to the evaporation of absorbed water because cellulose is highly hygroscopic (Owi et al. 2016). There were no substantial changes in the weight between 200 and $300{ }^{\circ} \mathrm{C}$; these ranges are associated with hemicellulose decompositions (Xiao et al. 2001). Hemicellulose is a heterogeneous polymeric network that has amorphous domains that attach to cellulose. In addition, it has a lower molecular weight; therefore, hemicellulose starts to degrade at temperatures as low as $200{ }^{\circ} \mathrm{C}$. There was approximately $50 \%$ weight loss observed in the second degradation process ranging between 250 to 350 ${ }^{\circ} \mathrm{C}$. Maximum decomposition was exhibited in this range, which is associated with cellulose decomposition ( $\mathrm{Ng}$ et al. 2015). Cellulose is a long linear chain of polysaccharides; hence it is more thermally stable. All isolated cellulose samples followed a similar degradation pattern with commercial cellulose (cellulose-c), as presented in Fig. 4. However, the decomposition temperatures of celluloses from rye, vetch, and barley were lower than celluloses from oat and clover, which may be due to the greater amount of crystalline cellulose present in later samples or lignin impurities in the samples. The final degradation temperature was observed above $350{ }^{\circ} \mathrm{C}$, which might be associated with lignin because lignin possesses a broad range of decomposition temperatures, from 250 to 
$600{ }^{\circ} \mathrm{C}$ (Xiao et al. 2001). Leftover char ( 20\%) was observed at temperatures above 450 ${ }^{\circ} \mathrm{C}$ in the case of celluloses from oat and clover, and this temperature was similar to the temperature with commercial cellulose residue, which indicated more carbon residues in these samples. Elemental oxygen and hydrogen are liberated to gaseous compound leaving only elemental carbon, lignin sample with higher $\mathrm{O} / \mathrm{C}$ ratio are expected to have a low residual carbon after heating (Gupta and Lee 2010). Thus, for samples with higher percentages of lignin and hemicellulose, there remained less amounts of residue after analysis. The residues left from the cellulose-rye and barley were around 13 to $14 \mathrm{wt} \%$ which was lower than the residues from other celluloses at $550{ }^{\circ} \mathrm{C}$ (Table 2). This may be due to the higher percentage of cellulose in other samples. The obtained results also indicated that the applied treatment methods in this study have a different yields of cellulose percentage with different plant biomass.

Table 2. Remained Weight (\%) in Samples During Temperature Graduation

\begin{tabular}{|c|c|c|c|c|c|c|}
\hline \multirow{2}{*}{$\begin{array}{c}\text { Temp. } \\
\left({ }^{\circ} \mathrm{C}\right)\end{array}$} & $\begin{array}{c}\text { Cellulose } \\
\text { (rye) }\end{array}$ & $\begin{array}{c}\text { Cellulose } \\
\text { (oat) }\end{array}$ & $\begin{array}{c}\text { Cellulose } \\
\text { (clover) }\end{array}$ & $\begin{array}{c}\text { Cellulose } \\
\text { (vetch) }\end{array}$ & $\begin{array}{c}\text { Cellulose } \\
\text { (barley) }\end{array}$ & $\begin{array}{c}\text { Cellulose-c } \\
\text { (commercial) }\end{array}$ \\
\hline 110 & 93.66 & 94.04 & 99.59 & 93.84 & 94.99 & 95.25 \\
\hline 250 & 90.65 & 92.32 & 96.91 & 91.37 & 90.82 & 93.16 \\
\hline 350 & 41.55 & 69.58 & 51.22 & 45.55 & 21.87 & 60.69 \\
\hline 450 & 13.87 & 22.32 & 20.89 & 15.98 & 12.56 & 21.79 \\
\hline
\end{tabular}

Interestingly, thermal degradation and residue percentage of oat and clover were similar to commercial cellulose. These results indicate that the celluloses derived from two cover crops (black oat and crimson clover) have a higher thermal resistance than celluloses from other cover crops tested in this study. Understanding the degradation behavior of cellulose is vital to determine their potential applications, such as biocomposites. The thermal profiles revealed that cellulose derived from cover crops might be an excellent reinforcing agent to improve the thermal property in environmentally friendly biocomposite materials.

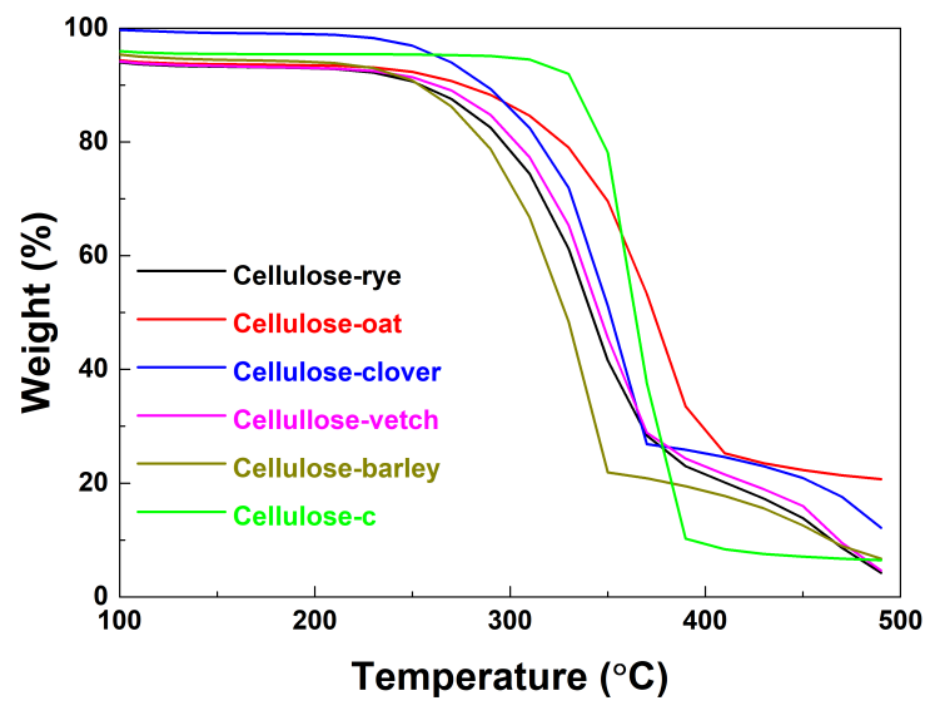

Fig. 4. Thermogravimetric curves of cellulose from cover crops and commercial cellulose (cellulose-c) 


\section{CONCLUSIONS}

1. Lignocellulosic components of five selected organic cover crops (rye, oat, clover, vetch, and barley) were successfully isolated and determined, and the results indicate that cover crops might be an alternative feedstock for biopolymers.

2. The structural variations of the isolated cellulose were successfully evaluated by FTIR and Raman Spectroscopy and exhibited similar spectral patterns with commercial cellulose, potentially indicating suitable for use in the polymer industry.

3. Among the cover crops tested in the present study, cellulose derived from black oat exhibited the highest thermal decomposition temperature $\left(\sim 370^{\circ} \mathrm{C}\right)$, which was even higher than commercial cellulose. Therefore, it is suggested that black oat might be a good candidate as a biopolymer in a sustainable application that requires relatively high-temperature use, such as microwaveable materials.

\section{Author Contributions}

N. S. designed and performed the experiments, analyzed the data, and prepared the manuscript. B. M. conceived and designed the study, reviewed and edited the manuscript, and supervised the research. G. J. conducted the experiments.

\section{ACKNOWLEDGMENTS}

The authors are grateful for the financial support of the United States Department of Agriculture (USDA) / National Institute of Food and Agriculture (NIFA), grant \# 201538821-24376. The authors would like to thank Dr. Kokoasse Kpomblekou-A for providing the samples and Dr. Nar Gurung for laboratory use for fiber analysis.

\section{Conflicts of Interest}

The authors declare no conflict of interest.

\section{REFERENCES CITED}

Agarwal, U. P. (2017). "Raman spectroscopy in the analysis of cellulose nanomaterials," In: Nanocelluloses: Their Preparation, Properties, and Applications, ACS Symposia, Washington, DC, pp. 75-90. DOI: 10.1021/bk-2017-1251.ch004

Agarwal, U. P., Reiner, R. R., and Ralph, S. A. (2013). "Estimation of cellulose crystallinity of lignocelluloses using near-IR FT-Raman spectroscopy and comparison of the Raman and Segal-WAXS methods," Journal of Agricultural and Food Chemistry 61(1), 103-113. DOI: 10.1021/jf304465k

Ajao, O., Marinova, M., Savadogo, O., and Paris, J. (2018). "Hemicellulose based integrated forest biorefineries: Implementation strategies," Industrial Crops and Products 126, 250-260. DOI: 10.1016/j.indcrop.2018.10.025

Akerholm, M., Hinterstoisser, B., and Salmen, L. (2003). "Characterization of the crystalline structure of cellulose using staticand dynamic FT-IR spectroscopy." Carbohyrdate Research 339, 569-578. 
Asim, N., Emdadi, Z., Mohammad, M., Yarmo, M. A., and Sopian, K. (2015). "Agricultural solid wastes for green desiccant applications: An overview of research achievements, opportunities and perspectives," Journal of Cleaner Production 91, 2635. DOI: 10.1016/j.jclepro.2014.12.015

Behera, S., Arora, R., Nandhagopal, N., and Kumar, S. (2014). "Importance of chemical pretreatment for bioconversion of lignocellulosic biomass," Renewable and Sustainable Energy Reviews 36, 91-106. DOI: 10.1016/j.rser.2014.04.047

Bundhoo, Z. M. A., and Mohee, R. (2018). "Ultrasound-assisted biological conversion of biomass and waste materials to biofuels: A review," Ultrasonics Sonochemistry 40, 298-313. DOI: 10.1016/j.ultsonch.2017.07.025

Chandel, A. K., Garlapati, V. K., Singh, A. K., Antunes, F. A. F., and da Silva, S. S. (2018). "The path forward for lignocellulose biorefineries: Bottlenecks, solutions, and perspective on commercialization," Bioresource Technology 264, 370-381. DOI: 10.1016/j.biortech.2018.06.004

Coblentz, W. K., Akins, M. S., Kalscheur, K. F., Brink, G. E., and Cavadini, J. S. (2018). "Effects of growth stage and growing degree day accumulations on triticale forages: 2. In vitro disappearance of neutral detergent fiber," Journal of Dairy Science 101(10), 8986-9003. DOI: 10.3168/jds.2018-14867

Das, A. M., Ali, A. A., and Hazarika, M. P. (2014). "Synthesis and characterization of cellulose acetate from rice husk: Eco-friendly condition," Carbohydrate Polymers 112, 342-349. DOI: 10.1016/j.carbpol.2014.06.006

Dungani, R., Abdul Khalil, H. P. S., Aprilia, N. A. S., Sumardi, I., Aditiawati, P., Darwis, A., and Riza, M. (2017). "Bionanomaterial from agricultural waste and its application," Cellulose-Reinforced Nanofibre Composites: Production, Properties and Applications, Elsevier Ltd. DOI: 10.1016/B978-0-08-100957-4.00003-6

Godin, B., Agneessens, R., Gerin, P. A., and Delcarte, J. (2011). "Composition of structural carbohydrates in biomass: Precision of a liquid chromatography method using a neutral detergent extraction and a charged aerosol detector," Talanta 85(4), 2014-2026. DOI: 10.1016/j.talanta.2011.07.044

Gupta, R., and Lee, Y.Y. (2010). "Investigation of biomass degradation mechanism in pretreatment of switchgrass by aqueous ammonia and sodium hydroxide," Bioresour. Technol. 101, 8185-8191. DOI:10.1016/j.biortech.2010.05.039

Jin, X., Chen, X., Shi, C., Li, M., Guan, Y., Yeon, C., and Peng, J. (2017). "Bioresource technology determination of hemicellulose, cellulose and lignin content using visible and near infrared spectroscopy in Miscanthus sinensis," Bioresource Technology 241, 603-609. DOI: 10.1016/j.biortech.2017.05.047

Johar, N., Ahmad, I., and Dufresne, A. (2012). "Extraction, preparation and characterization of cellulose fibres and nanocrystals from rice husk," Industrial Crops and Products 37(1), 93-99. DOI: 10.1016/j.indcrop.2011.12.016

Kauldhar, B. S., and Yadav, S. K. (2018). "Turning waste to wealth: A direct process for recovery of nano-silica and lignin from paddy straw agro-waste," Journal of Cleaner Production 194, 158-166. DOI: 10.1016/j.jclepro.2018.05.136

Kumar, P., Barrett, D. M., Delwiche, M. J., and Stroeve, P. (2009). "Methods for pretreatment of lignocellulosic biomass for efficient hydrolysis and biofuel production," Industrial and Engineering Chemistry Research 48(8), 3713-3729. DOI: 10.1021/ie801542g

Lee, H. V., Hamid, S. B. A., and Zain, S. K. (2014). "Conversion of lignocellulosic biomass to nanocellulose: Structure and chemical process," Scientific World Journal 
2014, Article ID 631013. DOI: 10.1155/2014/631013

Lupoi, J. S., Singh, S., Simmons, B. A., and Henry, R. J. (2014). "Assessment of lignocellulosic biomass using analytical spectroscopy: An evolution to highthroughput techniques," Bioenergy Research 7(1), 1-23. DOI: 10.1007/s12155-0139352-1

Makarem, M., Lee, C. M., Kafle, K., Huang, S., Chae, I., Yang, H., and Kim, S. H. (2019). "Probing cellulose structures with vibrational spectroscopy," Cellulose 26(), Springer Netherlands. DOI: 10.1007/s10570-018-2199-z

Mandal, A., and Chakrabarty, D. (2011). "Isolation of nanocellulose from waste sugarcane bagasse (SCB) and its characterization," Carbohydrate Polymers 86(3), 1291-1299. DOI: 10.1016/j.carbpol.2011.06.030

Ng, H. M., Sin, L. T., Tee, T. T., Bee, S. T., Hui, D., Low, C. Y., and Rahmat, A. R. (2015). "Extraction of cellulose nanocrystals from plant sources for application as reinforcing agent in polymers," Composites Part B: Engineering 75, 176-200. DOI: 10.1016/j.compositesb.2015.01.008

Owi, W. T., Lin, O. H., Sam, S. T., Chia, C. H., Zakaria, S., Mohaiyiddin, M. S., and Akil, H. M. (2016). "Comparative study of microcelluloses isolated from two different biomasses with commercial cellulose," BioResources 11(2), 3453-3465. DOI: 10.15376/biores.11.2.3453-3465

Panthapulakkal, S., and Sain, M. (2012). "Preparation and characterization of cellulose nanofibril films from wood fibre and their thermoplastic polycarbonate composites," International Journal of Polymer Science, Article ID 381342. DOI: $10.1155 / 2012 / 381342$

Poletto, M., Ornaghi Júnior, H. L., and Zattera, A. J. (2014). "Native cellulose: Structure, characterization and thermal properties," Materials 7(9), 6105-6119. DOI: 10.3390/ma7096105

Qi, N., Hu, X., Zhao, X., Li, L., Yang, J., Zhao, Y., and Li, X. (2018). "Fermentative hydrogen production with peanut shell as supplementary substrate: Effects of initial substrate, $\mathrm{pH}$ and inoculation proportion," Renewable Energy 127, 559-564. DOI: 10.1016/j.renene.2018.05.018

Qu, T., Zhang, X., Gu, X., Han, L., Ji, G., Chen, X., and Xiao, W. (2017). "Ball milling for biomass fractionation and pretreatment with aqueous hydroxide solutions," ACS Sustainable Chemistry and Engineering 5(9), 7733-7742. DOI:

10.1021/acssuschemeng.7b01186

Rooney, W. L., Blumenthal, J., Bean, B., and Mullet, J. E. (2007). "Designing sorghum as a dedicated bioenergy feedstock," Biofuels, Bioproducts and Biorefining 1(2), 147 157. DOI: $10.1002 / \mathrm{bbb} .15$

Schenzel, K., Fischer, S., and Brendler, E. (2005). "New method for determing the degree of cellulose I crystallinity by means of FT Raman spectroscopy," Cellulose 12, 223-231. DOI: 10.1007/s10570-004-3885-6

Seta, F. T., An, X., Liu, L., Zhang, H., Yang, J., Zhang, W., and Liu, H. (2020). "Preparation and characterization of high yield cellulose nanocrystals (CNC) derived from ball mill pretreatment and maleic acid hydrolysis," Carbohydrate Polymers 234, 115942. DOI: 10.1016/j.carbpol.2020.115942

Siepmann, J., Siegel, R. A., and Rathbone, M. J. (2012). "Fundamentals and applications of controlled release drug delivery," Fundamentals and Applications of Controlled Release Drug Delivery 1-594. DOI: 10.1007/978-1-4614-0881-9

Soest, P. J. V. A. N., and Robertson, J. B. (1981). "The detergent system of analysis and 
its application to human food," The Analysis of Dietary Fiber in Food 123-158. DOI: 10.3168/jds.S0022-0302(91)78551-2

Stinner, W., Möller, K., and Leithold, G. (2008). "Effects of biogas digestion of clover/grass-leys, cover crops and crop residues on nitrogen cycle and crop yield in organic stockless farming systems," European Journal of Agronomy 29(2-3), 125134. DOI: $10.1016 /$ j.eja.2008.04.006

Subhedar, P. B., and Gogate, P. R. (2014). "Alkaline and ultrasound assisted alkaline pretreatment for intensification of delignification process from sustainable rawmaterial," Ultrasonics Sonochemistry 21(1), 216-225. DOI:

10.1016/j.ultsonch.2013.08.001

Szerencsits, M., Weinberger, C., Kuderna, M., Feichtinger, F., Erhart, E., and Maier, S. (2015). "Biogas from cover crops and field residues: Effects on soil, water, climate and ecological footprint," International Journal of Environmental and Ecological Engineering 9(4), 413-416.

van der Weijde, T., Alvim Kamei, C. L., Torres, A. F., Vermerris, W., Dolstra, O., Visser, R. G. F., and Trindade, L. M. (2013). "The potential of C4 grasses for cellulosic biofuel production," Frontiers in Plant Science 4(May), 1-18. DOI: 10.3389/fpls.2013.00107

Welker, C. M., Balasubramanian, V. K., Petti, C., Rai, K. M., De Bolt, S., and Mendu, V. (2015). "Engineering plant biomass lignin content and composition for biofuels and bioproducts," Energies 8(8), 7654-7676. DOI: 10.3390/en8087654

Xiao, B., Sun, X. F., and Sun, R. C. (2001). " Chemical, structural, and thermal characterization of alkali-soluble lignins and hemicelluloses, and cellulose from maize stems, rye straw, and rice straw," Polymer Degradation and Stability 74, 307319

Xu, H., Li, B., and Mu, X. (2016). "Review of alkali-based pretreatment to enhance enzymatic saccharification for lignocellulosic biomass conversion," Industrial and Engineering Chemistry Research 55(32), 8691-8705. DOI: 10.1021/acs.iecr.6b01907

Xu, N., Liu, S., Xin, F., Zhou, J., Jia, H., Xu, J., and Dong, W. (2019). "Biomethane production from lignocellulose: Biomass recalcitrance and its impacts on anaerobic digestion," Frontiers in Bioengineering and Biotechnology 7, 1-12. DOI: 10.3389/fbioe.2019.00191

Yahya, M. A., Al-Qodah, Z., and Ngah, C. W. Z. (2015). "Agricultural bio-waste materials as potential sustainable precursors used for activated carbon production: A review," Renewable and Sustainable Energy Reviews 46, 218-235. DOI: 10.1016/j.rser.2015.02.051

Zhang, T., Wyman, C. E., Jakob, K., and Yang, B. (2012). "Rapid selection and identification of Miscanthus genotypes with enhanced glucan and xylan yields from hydrothermal pretreatment followed by enzymatic hydrolysis," Biotech. Biofuels 5, article no. 56. DOI: 10.1186/1754-6834-5-56

Article submitted: March 24, 2020; Peer review completed: May 16, 2020; Revised version received and accepted: May 26, 2020; Published: June 2, 2020.

DOI: $10.15376 /$ biores. 15.3.5641-5652 